\title{
Comparison of ratio loaded and unloaded foot area of flat foot and healthy foot in younger adults
}

\author{
Gunawan Dwi Haryadi ${ }^{1, *}$, Dwi Basuki Wibowo ${ }^{1}$, Achmad Widodo ${ }^{1}$, and Agus Suprihanto $^{2}$ \\ ${ }^{1}$ Center for Biomechanics, Central Laboratory of Research and Services, Diponegoro University, \\ Indonesia \\ ${ }^{2}$ Center for Biomaterials, Central Laboratory of Research and Services, Diponegoro University, \\ Indonesia
}

\begin{abstract}
This study is aimed to investigate loaded and unloaded foot area ratio (RFA, ratio of foot area) as special tests for the basis of clinical examination of flat foot and healthy foot. Type of foot is determined by Cavanagh's arch indexes (AI) which is the ratio between mid foot area to entire footprint area excluding the toes. Type of foot is called high arch when $\mathrm{AI}<0.21$, normal/healthy foot when $0.26>\mathrm{AI} \geq 0.21$ and flat foot when $\mathrm{AI}>0.26$. The entire loaded foot and footprint area for evaluating AI derived from a digital footprint is modified from document scanner, while the entire unloaded foot area derived from a 3D scanner. One hundred and two healthy students $(87$ males and 15 females, average aged 20 years and average BMI $22.51 \mathrm{~kg} / \mathrm{m}^{2}$ ) is asked voluntarily for doing footprint and scan. From 102 subjects found 63 participants identified as flat foot and 31 subjects are healthy feet. This study proves that the higher the value of AI the higher the value of RFA and foot type can be predicted by the value of RFA. For type of foot is high arch $R F A<0.49$, for healthy foot $0.55>\mathrm{RFA} \geq 0.49$ and for flat foot $\mathrm{RFA}>0.55$.
\end{abstract}

\section{Introduction}

The foot supports the body weight and are subjected to many ground reaction forces during daily activities. Foot acts as a lever to resist thrust during walking, running and jumping. Arch is a segmental elevation of the foot which can be classified into three arches: medial longitudinal arch (MLA), lateral longitudinal arch and transverse arch [1]. Variation in the height of MLA leads to two main common foot deformities, pes planus (flat foot) and pescavus (high arch). Pes planus is a flat foot condition in which MLA diminishes, otherwise for high MLA is called pes cavus [2]. A normal foot must be plantigrade, have normal anatomical disposition and physiomechanics, be resilient with proper springiness to provide a rhythmic normal gait [3].

\footnotetext{
${ }^{1}$ Corresponding author: gunawan dh@engineer.com
} 
Some parameters are considered as the predisposing factors of flat foot, such as age, sex, body composition, family history, and types of footwear [4]. Males were twice more reliable to have flat foot than females. Overweight and obese children were more likely to have flat foot with proper weight [5].

Cavanagh's and Staheli's arch index were most commonly used for clinical diagnosis by using footprint. Cavanagh's arch index (AI) determine arch type from division of mid foot area to entire footprint area excluding the toes (Fig. 1a). If AI less than 0.21, arch type of foot is called high arch. If AI is between 0.21 and 0.26 , arch type of foot is called normal arch, and If AI is greater than 0.26, arch type of foot is called flat foot [6]. Staheli has characterized the width of the foot in the area of the arch and heel and the ratio between these widths was called the Staheli's plantar arch index (Fig. 1b) [7]. A normal plantar arch index (PI), according to the Pediatric Orthopaedic Society is the one comprised within 2 standard deviations (SD) of the population average. If PI values are equal or above the sum of 2 is considered as flat foot.

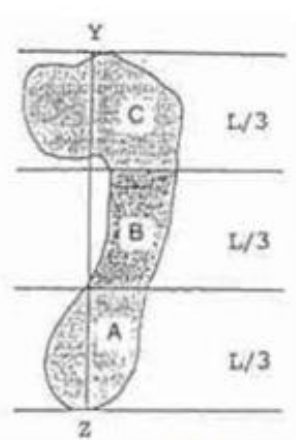

(a)

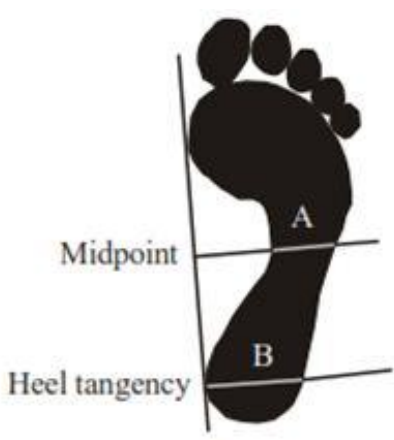

(b)

Fig. 1. Cavanagh's and Staheli's arch index

This study is aimed to investigate ratio loaded and unloaded foot area (RFA, ratio of foot area) as special tests for the basis of clinical examination of flat foot and healthy foot. Type of foot determine by Cavanagh's arch index (AI) where healthy foot is equal to normal foot. If this test showed the significant relationship between RFA to AI, than RFA can be used as an alternative tool for the diagnosis of types of foot which is simpler to apply.

\section{Methods}

This research is a cross sectional study. A total of 102 subjects comprising 87 males and 15 females, average aged 20 years (range 17-26 years) and average BMI $22.51 \mathrm{~kg} / \mathrm{m} 2$ (range $15.21-41.60 \mathrm{~kg} / \mathrm{m} 2$ ) were used for the study. The subjects are students of Mechanical Engineering Department of Diponegoro University, Semarang Indonesia. All subjects had no deformities of the lower limb or history of fractures of the foot based on the check up at Diponegoro National Hospital Semarang. The measurements of AI and foot area were carried out at the Center for Biomechanics, Biomechatronics, Biomaterials, and Biosignals Processing (CBIOM3S) of the Central Laboratory of Research and Services (UPT Lab. Terpadu) Diponegoro University.

For each subject, footprints were obtained using digital footprint modified from document scanner (Fig. 2a) [8]. To produce clear image, the amount of light from the environment must be minimized and the foot is cleaned by dipping into warm water $( \pm 30$ 
${ }^{\circ} \mathrm{C}$ ) for about 2-3 minutes and dried with tissue paper. The scanning process occurs when the research subject is really standing in an upright posture above the platform which can be assisted by the operator.

To calculate contact area with and without the toes, uncontacted foot must be removed using MATLAB Software. The procedure is as follows: 1) read the footprint image (Fig.2b) using imread function, 2) change the RGB image to gray scale image using rgb2gray function, 3) input the index level of image for filtering, 4) change the grayscale image to black and white image with $i m 2 b w$ function [9]. The results are obtained only images foot in contact as apparent in Fig. 2c. Calculating the entire loaded foot area (including the toes) is done by using bwarea function in MATLAB, but it is still in pixel unit. To change the foot area in pixels to $\mathrm{mm}^{2}$, scanner resolution data is needed. The scanner is set to scan in 200 ppi (default setting of scanner). The entire loaded foot area can be measured by using equation 1 as shown:

$$
\left(\frac{\text { area in pixels }}{\text { scanner resolution }}\right) \times 645.16 \mathrm{~mm}^{2}
$$

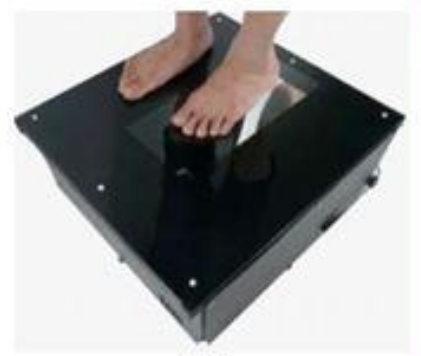

(a)

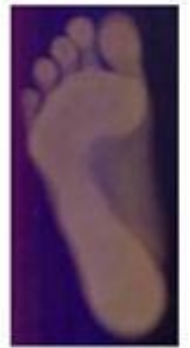

(b)

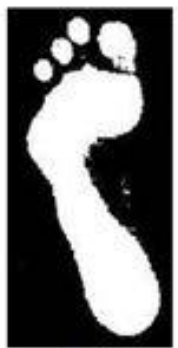

(c)

Fig. 2. Scanning of the foot using flatbed document scanner

The Cavanagh's arch index is calculated using MATLAB through the following procedures: 1) read the footprint image Fig. 2c and remove the toes using bwareaopen function, 2) use imcrop function to cut the image in the upper and lower limits, 3) divide image into 3 regions at the same length (Fig. 1a), 4) calculate the area of each region using bwarea and divide the middle third area with all area of footprint without the toes. Equation 2 shows the calculation of $\mathrm{AI}$ as follow:

$$
A I=\frac{B}{(A+B+C)}
$$

Where A, B and C are rear foot area, mid foot area and fore foot area respectively.

\section{Results}

Subjects were divided into 3 groups according to their foot types (Table 1). High archs comprising 7 males and 1 female with average AI $0.182 \pm 0.027$ (range 0.125 to 0.204 ) and average RFA $0.46 \pm 0.04$ (range 0.388 to 0.539 ), healthy feet comprising 28 males and 3 females with average AI $0.236 \pm 0.015$ (range 0.210 to 0.260 ) and average RFA $0.52 \pm 0.05$ 
(range 0.437 to 0.607 ) and flat feet comprising 52 males and 11 females with average AI $0.319 \pm 0.040$ (range 0.261 to 0.385 ) and average RFA $0.61 \pm 0.09$ (range 0.400 to 0.860 ).

Table 1. Average AI and RFA of the subjects according to foot types.

\begin{tabular}{|l|c|c|c|c|c|c|c|}
\hline $\begin{array}{c}\text { Foot } \\
\text { type and } \\
\text { Gender }\end{array}$ & Amounts & $\begin{array}{c}\text { Age } \\
(\text { years })\end{array}$ & $\begin{array}{c}\text { BMI } \\
\left(\mathrm{kg} / \mathrm{m}^{2}\right)\end{array}$ & AI & $\begin{array}{c}\text { LFA } \\
\left(\mathrm{mm}^{2}\right)\end{array}$ & $\begin{array}{c}\text { ULFA } \\
\left(\mathrm{mm}^{2}\right)\end{array}$ & RFA \\
\hline High arch & 7 & $\begin{array}{c}20.29 \\
(1.60)\end{array}$ & $\begin{array}{c}21.00 \\
(4.26)\end{array}$ & $\begin{array}{c}0.190 \\
(0.015)\end{array}$ & $\begin{array}{c}9393.29 \\
(1092.45)\end{array}$ & $\begin{array}{c}20657.71 \\
(1157.99)\end{array}$ & $\begin{array}{c}0.45 \\
(0.05)\end{array}$ \\
\hline Male & 1 & 23.00 & 16.85 & 0.125 & 7455.00 & 15535.00 & 0.48 \\
\hline Female & 1 & $\begin{array}{l}20.14 \\
(2.01)\end{array}$ & $\begin{array}{c}22.01 \\
(3.52)\end{array}$ & $\begin{array}{c}0.238 \\
(0.015)\end{array}$ & $\begin{array}{c}10906.46 \\
(1113.55)\end{array}$ & $\begin{array}{c}20855.93 \\
(1686.97)\end{array}$ & $\begin{array}{c}0.52 \\
(0.05)\end{array}$ \\
\hline Healthy foot \\
\hline Male & 28 & $\begin{array}{c}21.33 \\
(4.04)\end{array}$ & $\begin{array}{c}19.69 \\
(3.93)\end{array}$ & $\begin{array}{c}0.218 \\
(0.011)\end{array}$ & $\begin{array}{c}7763.33 \\
(573.93)\end{array}$ & $\begin{array}{c}15799.33 \\
(952.52)\end{array}$ & $\begin{array}{c}0.49 \\
(0.05)\end{array}$ \\
\hline Female & 3 & $\begin{array}{l}19.98 \\
(1.90)\end{array}$ & $\begin{array}{c}23.16 \\
(4.49)\end{array}$ & $\begin{array}{c}0.318 \\
(0.039)\end{array}$ & $\begin{array}{c}13134.18 \\
(2152.75)\end{array}$ & $\begin{array}{c}21354.19 \\
(1966.82)\end{array}$ & $\begin{array}{c}0.62 \\
(0.09)\end{array}$ \\
\hline Flat foot & 52 & $\begin{array}{l}19.18 \\
(1.17)\end{array}$ & $\begin{array}{c}22.93 \\
(3.75)\end{array}$ & $\begin{array}{c}0.319 \\
(0.046)\end{array}$ & $\begin{array}{c}10574.81 \\
(2068.15)\end{array}$ & $\begin{array}{c}18272.00 \\
(1269.30)\end{array}$ & $\begin{array}{c}0.58 \\
(0.10)\end{array}$ \\
\hline Male & 52 &
\end{tabular}

Values are expressed as mean \pm (standard deviation). AI, Cavanagh's arch index; LFA, loaded foot area; ULFA, unloaded foot area; and RFA, ratio of foot area $=$ LFA/ULFA

Fig. 3a shows the comparison between average AI and average RFA according to foot types. There was a significant relationship between average AI to average RFA which can be presented by linear regression (equation 3) with coefficient of correlation $r=0.99$ (Fig. 3b).

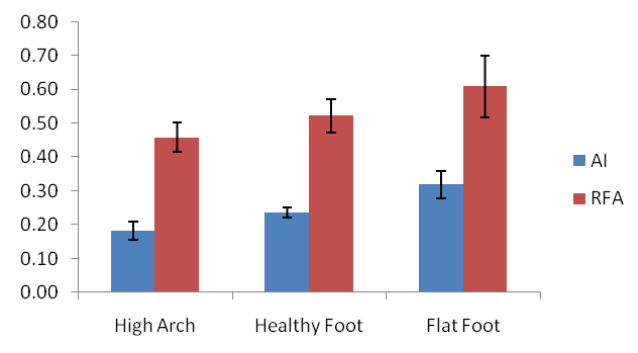

(a)

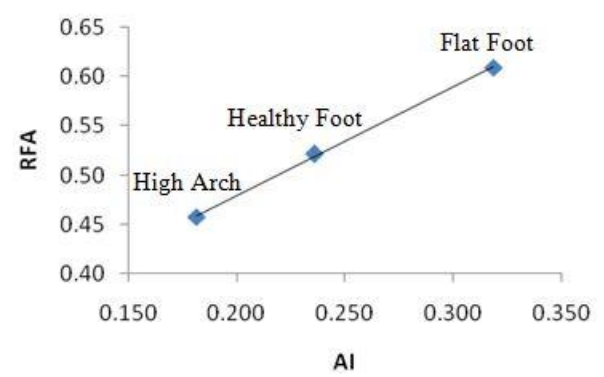

(b)

Fig. 3. Comparison and the relationship between AI and RFA according to foot types

The data showed that the overall prevalence of healthy foot and flat foot were $30.39 \%$ and $61.76 \%$ respectively. The prevalence of flat foot in male and female students are $50.98 \%$ and $10.78 \%$ respectively (Table 2 ) 
Table 2. The comparison of prevalence of healthy and flat foot (\%)

\begin{tabular}{|l|c|c|c|}
\hline Subjects & High arch & Healthy foot & Flat foot \\
\hline Male & 6.86 & 27.45 & 50.98 \\
\hline Female & 0.98 & 2.94 & 10.78 \\
\hline Total & 7.84 & 30.39 & 61.76 \\
\hline
\end{tabular}

\section{Discussion}

The current study shows that the prevalence percentage of flat foot among the total population is $61.76 \%$, two times greater than healthy foot [14-17]. Flat feet were high in males than females, the prevalence of flat feet was $50.98 \%$ in males and $10.78 \%$ in females. The prevalence percentage of flat feet were also higher $23.50 \%$ in males and $7.85 \%$ in females compared to the healthy feet [18-20].

The result of foot area found that male had significantly greater foot area than female. This result is corresponding to the research by Lee et al. [19], Periyasamy et al. [20] and Wunderlich et al [21]. The average LFA for normal feet are $10906.46 \mathrm{~mm}^{2}$ in males and $7763.33 \mathrm{~mm}^{2}$ in females and the average ULFA are $20855.93 \mathrm{~mm}^{2}$ in males and $15799.33 \mathrm{~mm}^{2}$ in females. Offcourse the average foot area of flat foot is greater than normal foot and male had significantly greater foot area than female too. The average LFA for flat feet are $13134.18 \mathrm{~mm}^{2}$ in males and $10574.81 \mathrm{~mm}^{2}$ in females and the average ULFA are $21354.19 \mathrm{~mm}^{2}$ in males and $18272.00 \mathrm{~mm}^{2}$ in females.

Because the result of measurement of LFA for flat foot are greater than healthy foot and increasing of ULFA for flat foot inversely linear with the increasing ULFA for healthy foot, offcourse RFA of flat foot is greater than healthy foot. The average RFA for healthy foot and flat foot are $0.52 \pm 0.05$ and $0.61 \pm 0.09$ respectively.

In this study the technique employed for obtaining footprints is simple, noninvasive, easy to apply and does not use radiation as well. This scanner can tackle shortage of wet foot test which is not accurate because of the difficulty of knowing that the subjects are standing in upright position when printing their foot at a piece of paper [22]. But the method for classifying foot types by Cavanagh's arch index is rather difficult compared to the Staheli's arch index [7][15]. From the result of this study which showed that significant correlation between AI and RFA, classifying foot types can be done simpler only by measuring LFA using flatbed document scanner and ULFA using 3D scanner compared to the Cavanagh's arch index.

\section{Conclusion}

This study proves that the higher the value of AI the higher the value of RFA and foot type can be predicted by the value of RFA. For type of foot is high arch RFA $<0.49$, for normal/healthy foot $0.55>\mathrm{RFA} \geq 0.49$ and for flat foot RFA $>0.55$.

The method for classifying foot types by calculation of the ratio entire loaded and unloaded foot area is simpler and easy to apply compared to the Cavanagh's AI. It is not necessary to divide the footprint image (without the toes) into 3 regions and calculating the area of each region which rather difficult to build in application software. Even the footprint image can be done by wet foot test with a little bit carefully on a piece of paper chart and the entire loaded foot area is calculated by the amount of squares which printed ink on paper.

This work was supported by the Application and Development Research Grant UNDIP Contract No: SP DIPA - 042.01.2.400898/2016 


\section{References}

1. L.T. Staheli, D.E. Chew, M. Corbett, The longitudinal arch. J Bone Joint Surg Am, 69, 426-8 (1987)

2. D.H. Van Boerum, B.J. Sangeorzan, Biomechanics and pathophysiology of flat foot. Foot Ankle Clin, 8, 419 (2003)

3. A.E. Hunt, R.M. Smith, Mechanics and control of the flat versus normal foot during the stance phase of walking. Clin Biomechanics, 19, 391-7 (Bristol, Avon 2004)

4. T. Abolarin, A. Aiyegbusi, A. Tella, Predictive factors for flatfoot: The role of age and footwear in children in urban and rural communities in South West Nigeria. The Foot 21, 188-192 (2011)

5. A. Evans, K. Rome, Cochrane review of the evidence for non-surgical interventions for flexible pediatric flat feet. Eur. J. Phys. Rehab. Med, 47, 69-89 (2011)

6. R. Peter, Cavanagh, M.M. Rodgers, The Arch index: a useful measure from footprints, 20(5), 547-551 (J. Biomechanics, 1987)

7. A.J. Hernandez, L.K Kimura, M.H.F Laraya, Calculation of staheli's plantar arch index and prevalence of flat feet: a study with 100 children aged 5-9 years, 15(2), 68-71 (Acta Ortop Bras, 2007)

8. D.B. Wibowo, G.D. Haryadi, A. Widodo, et al, Estimation of calcaneal loading during standing from human footprint depths using 3D scanner. AIP Conf. Proc. 1788, 030063-1-030063-9, doi 10.1063/1.4968316 (Acta Ortop Bras, 2007)

9. R.C Gonzalez, R.E Woods, S.L Eddins, Digital Image Procesing Using MATLAB. 2, (Gatesmark Publishing, A Division of Gatesmark, LLC 2009)

10. R.I. Harris, T. Beath, Army foot survey: an investigation of foot ailments in Canadian soldiers, 116 (1947)

11. PS Igbigbi, BC Msamati, MB Shariff, Arch index as a predictor of pes planus: a comparative study of indigenous Kenyans and Tanzanians. J Am Podiatr Med Assoc, 95(3), 273-6 (2005)

12. S. Yucesan, H. Dindar, I. Olcay, H. Okur, S. Kilicaslan, Y. Ergoren, et al, Prevalence of congenital abnormalities in Turkish school children, 9(4), 373-80 (Eur J Epidemiol, 1993)

13. B. Alamy, An epidemiologic study of flat foot in Iran, 55(3-4), 78-83 (Tehran Univ Med J, 1997)

14. A.K Reihaneh, F. Aliabadi, Prevalence of flat feet: Comparison between male and female primary school students. Iranian Rehabilitation Journal, 11, 18 (2013)

15. H.H. Hazzaa, G.H. El-Meniaway, S.E. Ahmed, M.B. Bedier, Correlation between gender and age and flat foot in obese children, 10(4), 207-215 (2015)

16. J.H. Chang, C.L. Wang, Y.W. Shen, L.C Hong, Prevalence of flexible flatfoot in Taiwanese school-aged children in relation to obesity, gender and age, 169, 447-452 (2010)

17. Lee, Yu-Chi, Lin, Gloria, J Wang, Mao-Jiun, Comparing 3D foot scanning with conventional measurement method. Journal of Foot and Ankle Research, 7, 44 (2014)

18. R. Periyasamy, et al, Preliminary investigation of foot pressure distribution variation in men and women adults while standing, 142 - 148 (The Foot 21, 2011)

19. R.E. Wunderlich, P.R. Cavnagh, Gender differences in adult foot shape: Implications for shoe design, 33, 605-611 (Med. Sci. Sports Exer, 2001)

20. R. Stephen, Urry, S.C. Wearing, Comparison of footprint indexes calculated from ink and electronic footprints, 91(4), 203-209 (J Am Podiatr Med Assoc, 2001) 